\title{
Homogeneous Metal Foam Manufacturing and Impact Test Performance
}

\author{
Ananthakrishnan Kaimal*, Bevin Boban Mathew, and S. Jeyanthi \\ School of Mechanical And Building Sciences, Vellore Intsitute of Technology, Chennai, 600127, India
}

\begin{abstract}
In this investigation, metal foam was produced by casting aluminum around intersecting ceramic cylinders. Through this study, an attempt was made to propose the use of homogeneous metal foams in impact attenuation. The metal foam in this investigation was made using a novel casting method. The testing was done on a UTM and subsequent simulations on an explicit dynamic solver in an ABAQUS environment. The crash simulation is initiated after a certain level of similarity between results of the UTM compression test and FEM compression analysis. The results demonstrate that a compact and cheap impact energy absorption unit can be made using the described method. The simulation compares a solid block to the obtained foam in terms of "Energy absorption per unit volume" and total kinetic energy of the impact test set-up.
\end{abstract}

Keywords: metal foam; ceramic cylinders; homogeneous foam; impact absorbing; casting; compression test; crash simulation

(Submitted on June 16, 2019; Revised on July 18, 2019; Accepted on August 30, 2019)

(C) 2019 Totem Publisher, Inc. All rights reserved.

\section{Introduction}

Foams of different materials have been in use for some time now. It has been of great interest because of the fact that all natural stress bearing structures are cellular in nature such as wood, bone, fiber etc. Metallic foams consist of a new class of materials that turned out to be promising in different engineering fields. In the present scenario, the metal foam finds limited useful applications such as a core for sandwich panel structure, heat exchangers, and filters in industrial sectors like automotive, aerospace, and ship manufacturing [1-4]. Metal foam has a very interesting combination of low density, high energy absorption properties etc. [1-2]. But, for a design engineer who intends to use metallic foam in his/her project, the main challenge working with metallic foam is to rely on the statistical data of the stock material rather than traditional engineering data. The unavailability of the engineering data can be attributed to the inherent irregularity and stochastic nature of the foam cell structure. But designers need not only experimental data, but also a reliable and relatively simple analytical or numerical method for calculation of applied stress and for prediction of failure of metallic foam. In that perspective, the engineering potential of cellular materials is considerable, but its realization requires new and innovative methods of design, which is unfamiliar to traditional engineers. Adding to this problem is the new legislation coupled with important marketing advantages that has emphasized the need for structural systems with documented crash worthiness integrity.

Of all the methods, casting is considered to be the one of the most economic as well as most controllable method. Casting provides the engineers with the most desirable options to control parameters [5-6]. The parameters of the foam that determine its general physical properties are cell size, shape, and wall thickness [7]. These processes in general can be controlled by ceramic pellets, spheres or like in our case, ceramic columns. The interstitial space between ceramic structures are infiltrated by molten metal. There are examples of metal foam manufacturing using ceramic spherical balls in ordered arrangements [8]. But, in that particular example, a foreign material i.e. ceramic core was left in the aluminum matrix. Whereas in the ceramic cylindrical column method, once the casting process was completed, the ceramic residue was removed completely, leaving no contaminants in the aluminum matrix.

Smith [9] extensively discussed structural application, manufacturing, material properties and modeling of steel foam, stating an important new parameter. It introduced density as a deciding factor in the properties of foam. They demonstrated

\footnotetext{
* Corresponding author.

E-mail address: ananthakrishnangirish.kaimal2015@vit.ac.in
} 
that controlling density can significantly alter different components of performance. Altering density can change stiffnessweight ratio, energy dissipation and thermal resistivity. Avandi [10] conducted experimental work on energy absorption of metallic foams. They conducted a dynamic test using a split Hopkinson pressure bar. This is an example where they performed extensive dynamic testing rather than quasi-static testing and thus providing a lot of information which earlier unknown. The testing to establish size independent results for further research reference. The research work also extends into dependency of the properties to strain rate, as it has been discussed to use of metallic foam as a ballistic armor. The armor used boron-carbide ceramics and metallic foam with a combination of Kevlar plates [11]. The foam used in this experiment was steel spheres embedded in stainless steel matrix. Of the total energy absorbed by the assembly, the foam absorbed $60 \%$ to $70 \%$ of the total kinetic energy. This again proves the usefulness of metal foam as an impact attenuator. Qin et al [12] focused on indentation experiments on the foam. They revealed that the dependence of plastic bending and stretching in the local deformation regions interferes with the results of indentation. They also revealed the existence of membrane force in the penetration of the foam when depth is more than the initial wall width. Energy absorption by axial crushing of the thin-walled tubes made of mild steel was recognized by [13]. A simple expression for average crushing force was also deduced by [13]. Energy absorption capabilities of thin walled tubes filled with foam has been investigated [13-19]. Recent technologies focus on the use of aluminum foam as the stand-alone structure for energy absorption. New manufacturing methods in addition to high strength to weight ratio makes the use of these foams attractive for commercial use. While the research has been extensively carried out in order to make a statistical based CAD model for the Finite Element method, miniscule work has been done to develop a uniform cell-structured foam. Some of the few works done to analyze regular or random arrangements using ceramic spherical spheres using modelling and finite element methods is relevant to the topic [20-21].

In this study, metal foam of homogeneous cell patterns were formed using an advanced variation of the lost foam casting process. The work comprises of machining of a polymer foam to make intersecting channels. The channels will be later filled with ceramic slurry, which is plastic-setting in nature. Once the channels are set, the polymer foam is heated to its vaporisation temperature. This causes the polymer around the channels to vaporise, leaving the channels core structure alone. The channels core structure is then placed in a mold and the structure is cast using aluminum. The resultant structure is de-contaminated and tested. The stress-strain pattern, energy absorption and numerical calculations are performed to evaluate the product.

\section{Solution}

The casting method: one of the approaches for production of metal foams is a melting process that provides a researcher with desirable options. In general, the physical and mechanical properties of metal foams are related to their cellular structure. Cell size, shape, and wall thickness are significant characteristics of these materials, which in the casting approach are controlled by hollow intersecting channels that crosses through the mass of the prototype in three axes as shown in Figure 1. These intersecting channels create a chain of repeating stress bearing units, which are predominantly of the same size throughout the material. See Figure 2. Table 1 shows the property defining parameters of the foam.
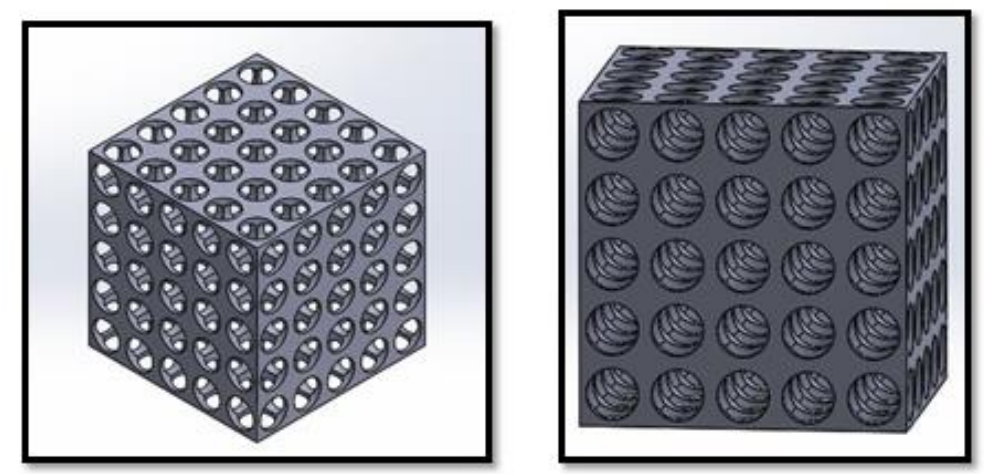

Figure 1. Prototype CAD model

Table 1. Technical specification of the product

\begin{tabular}{|c|c|}
\hline Size & $75 \times 60 \times 85 \mathrm{~mm}$ \\
\hline Wall thickness & $5.0 \mathrm{~mm}$ \\
\hline Cell size & $8.0 \mathrm{~mm}$ (side circle diameter) \\
\hline Cell shape & Skewed Dodecahedron \\
\hline Structural material & Aluminum \\
\hline
\end{tabular}




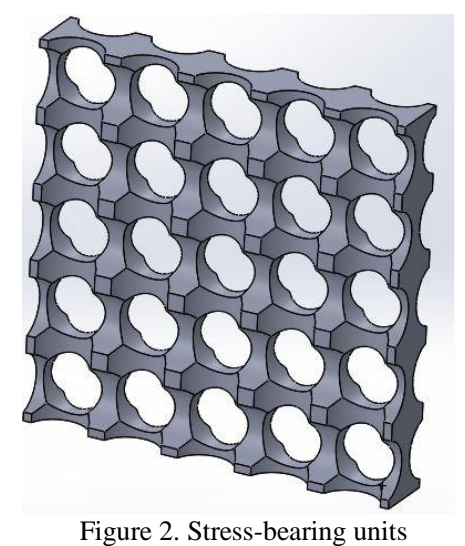

\section{Methodology}

The approach chosen for the fabrication process is the lost foam casting process using polymer foam and a ceramic-resin core filling. A foam needs to be chosen for the lost foam casting process. The important parameters for foam selection is excellent machinability and a low melting point. Therefore, a high-density polyethylene foam block of $65 \times 60 \times 75$ is taken as the base foam for the first casting process. The next step is drilling holes perpendicular to the surface up to the opposite surface. Holes of $8 \mathrm{~mm}$ diameter are used in this prototype. A distance of $13 \mathrm{~mm}$ was laid between the channel centers to maintain $5 \mathrm{~mm}$ wall thickness. The refractory mixture produced by the mixture of sand was $80 \%$ wt. and plastic mix $20 \%$ wt. See Table 2. This refractory material is then filled into the channels. The filling process was done by placing the foam block on a flat surface and covering the side perpendicular to the ground with a long piece of single cardboard folded to subsume the sides other than the top side, which was the entry point for the mixture.

Table 2. Composition (wt. \%) of sand and (vol. \%) epoxy based plastic mix used in ceramic core
\begin{tabular}{|c|c|}
\hline Content & Weight percentage \\
\hline $\mathrm{Al}_{2} \mathrm{O}_{3}$ & $60 \%$ \\
\hline $\mathrm{SiO}_{2}$ & $35 \%$ \\
\hline $\mathrm{Fe}_{2} \mathrm{O}_{3}$ & $<3 \%$ \\
\hline $\mathrm{TiO}_{2}$ & $<3 \%$ \\
\hline $\mathrm{K}_{2} 0$ & $<3 \%$ \\
\hline Epoxy based plastic mix & Volume percentage \\
\hline Epoxy resin & $90 \%$ \\
\hline Formahaldyhyde hardener & $10 \%$ \\
\hline
\end{tabular}

Once the channels are filled with the mixture, the block is kept at room temperature for plastic formation. The setting time for the used mixture is about 12 hours. After a period of 12 hours, the plastic mixture is checked for hardness. After a satisfactory level of hardness is achieved, the block is taken for foam vaporization. The vaporization is done by exposing the foam block to an air temperature of $650^{\circ} \mathrm{C}$. The heat instantly melts and then vaporizes the foam, leaving behind the solidified refractory structures. This refractory structure would be used as the core for the casting process. A major challenge in the experiment was to control the plastic decomposition during casting using the insulation property of the sand. An experiment was conducted where 10 grams of hardened mixture was heated to $650^{\circ} \mathrm{C}$ for 60 seconds. The result was that the outer plastic layer decomposed, but the internal structure remained intact. So, the method was accepted. This refractory mixture was injected into the channels until all the channels were completely filled.

\subsection{Casting Process}

Aluminum was melted in a furnace at $900^{\circ} \mathrm{C}$ and the mold was prepared using standard foundry sand. The mold used was an open-type with a crown at the opening to use as a sprue reservoir. The core was heated to $300^{\circ} \mathrm{C}$ using an industrial hot air blower. The preheating was done to slow down the cooling of melted aluminum (shown in Figure 3).

\subsection{Cast Analysis}

The core structure was removed using a conventional drilling process. The core had lost its hardness as a result of the decomposition of plastic. During the casting process, the melted aluminum cooled too fast and solidified after subsuming the first layer cell structured void. The resultant structure was a 2D cellular structure. 

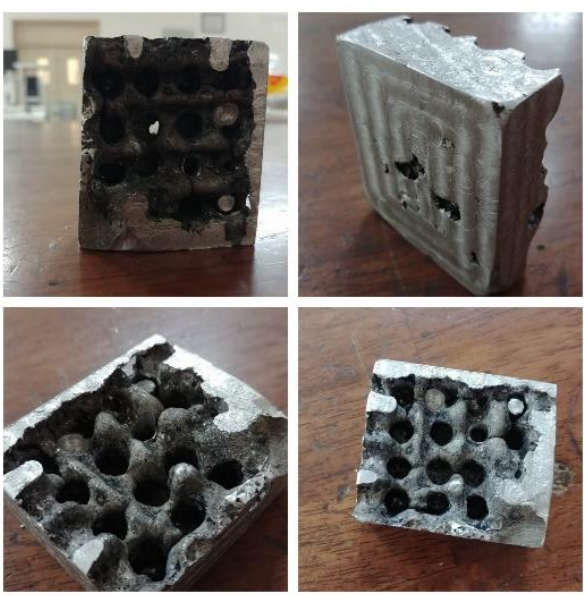

Figure 3. Final cast product

\section{Testing and Analysis}

Considering the nature of the application, it is obvious that the most relevant method to test the product is impact analysis. But, the most common method for testing an object's energy absorbing capacity is to measure its energy absorption per unit volume given by (1). For the energy absorption per unit volume, the test that needs to be conducted is the constant hammer speed compression test. Since the one of the project's main objective was to make the product compatible with FEM, the decision was taken to do the compression as well as the crash test through FEM while validating the results of compression with actual UTM testing. Another important reason we chose FEM was the inability of the destructive testing methods to obtain exact stress value for non-standard components. The method involves development of a CAD model that imitates the result of the original product when subjected to similar test conditions. After the development of the CAD model, the rest of the analysis was carried out in the FEM environment. The FEM tool used was ABAQUS.

\subsection{UTM Testing}

The testing (shown in Figure 4) was focused of the energy absorption property of the obtained sample of metal foam. The method chosen was the standard stress-strain integration method, which is the preferred method. The test was conducted in a UTM machine with a maximum load of $49.066 \mathrm{KN}$. The compression test was carried out in a constant hammer speed mode with a speed of $1 \mathrm{~mm} / \mathrm{min}$.

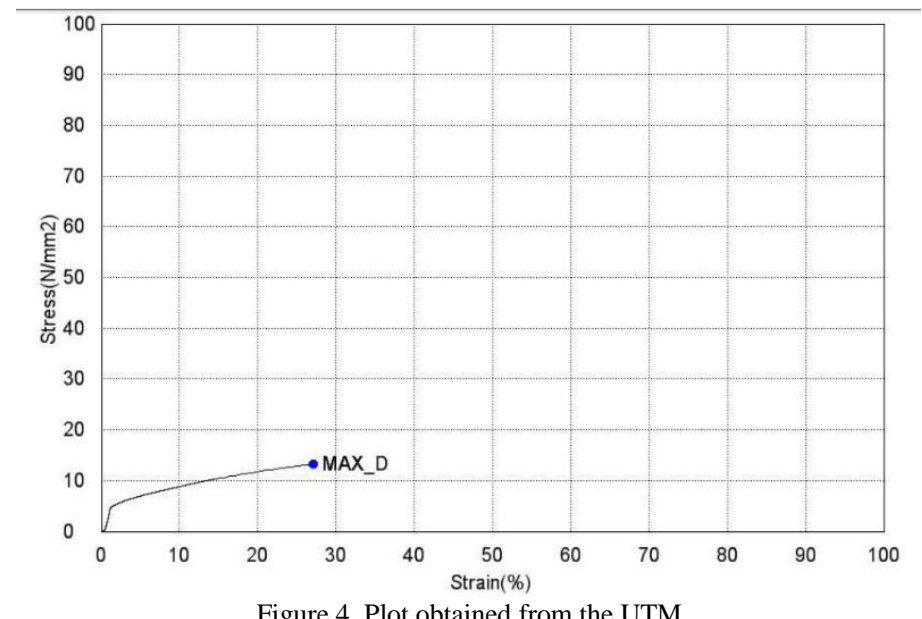

\subsection{Analysis}

The actual results came from the FEM analysis part of the testing since the prime motive of the work was to make the foam FEM environment more friendly. Hence, the first CAD model of the cast product was developed. The developed CAD model was meshed in an ABAQUS environment. The CAD model was put under compression analysis and the resultant 
stress-strain plot was compared with the original UTM generated plot. The CAD model was put through a series of modifying iterations until the analysis stress-strain plot is simmilar to that of the UTM generated plot. The final iteration of the CAD model performed similarly to the actual cast product and was finalised for further simulation (shown in Figure 5).

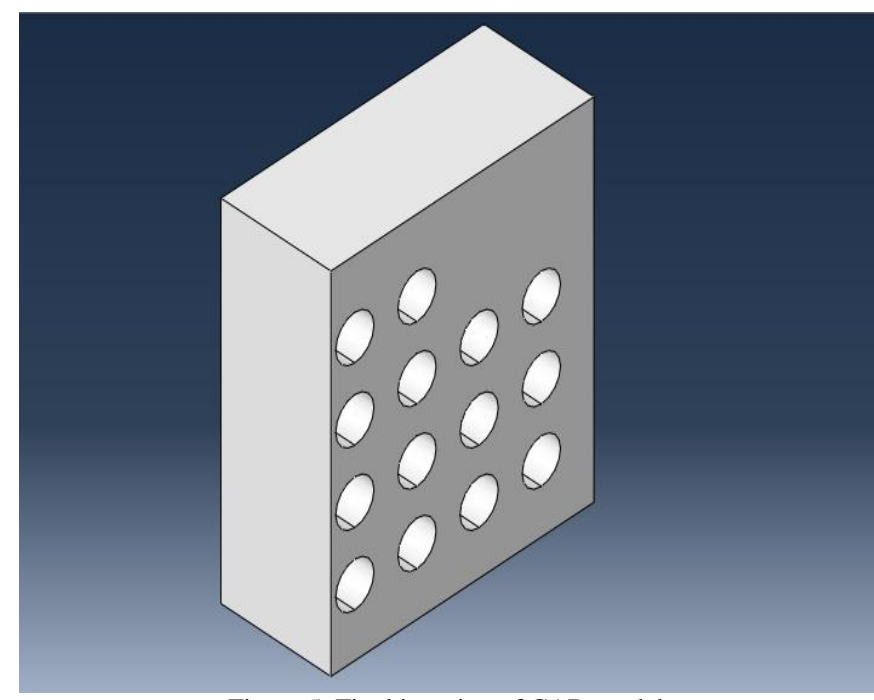

Figure 5. Final iteration of CAD model

Figure 6(a) shows the stress-strain plot obtained using the ABAQUS solver. The plot that scalled shows a very simmilar strain pattern to the UTM plot.The method by which the capacity of a mass can absorb energy per unit volume is given by (1)

$$
W=\int \varepsilon \sigma(\varepsilon) \mathrm{d} \varepsilon
$$

Hence, inegrating the stress strain curve w.r.t. strain will give Figure 6(b). The area under the curve in Figure 6(b) is the capacity of the mass to absorb energy. The same compression simulation was repeated on a solid aluminum block of identical dimensions of the superstructure of the cast foam. Figure 7(a) shows the stress-strain curve of the solid aluminium block. Figure 7(b) shows the integration curve. The integration curve of both foam and solid metal looks simmilar, but a close exmination reveals that the peak stress values in the case of foam was $60 \times 10^{6} \mathrm{~Pa}$ at $0.8 \%$ strain of the height in the case of solid structure, and the peak value was $0.8 \times 10^{5} \mathrm{~Pa}$ at $0.0275 \%$ strain of the height. Hence, the results conclusively prove that the area under the stress strain curve in the foam is larger than that of the solid block. It is therefore a better impact attenuator than a solid block of aluminum. We further tested the impact simulation in the ABAQUS environment. The test was conducted in accordance with FMVSS 208 (American NCAP), which specifies the high impact velocity to be at $56 \mathrm{~km} / \mathrm{h}$. The analysis conditions are such that the foam block is kept stationary as well as encastered. The moving object (hammer) is positioned to make an impact at $56 \mathrm{Km} / \mathrm{h}$ with the stationary foam. The analysis on equivalent aluminum blocks are also conducted. The analysis results are studied with the help of a plot of the kinetic energy of the hammer vs time. Figure 8 represents the impact of the hammer with the solid Aluminum block. Figure 8 shows that the hammer lost $0.02 \times$ $10^{12}$ Joules of energy in 0.015 seconds from the impact with the solid aluminum block. Figure 9 shows that the hammer lost $0.03 \times 10^{12}$ Joules of energy in 0.015 seconds. Therefore, it proves that the foam block obtained in the novel method of fabrication can absorb more energy than a normal aluminum block. In Figure 8, the vertical line from the x-axis meets the curve to show the time period of the initial impact absorbtion. The horizantal line shows the estimate time period, which is 0.0025 seconds in the case of the solid aluminum block. In 0.0025 seconds, the energy of the body reduces by $0.41875 \times 10^{12}$ Joules. While in the case of themetal foam, the time period of initial impact energy absorption was 0.005 seconds and in the same time period, the energy was reduced to $0.425 \times 10^{12}$ Joules.

The solid block gives a reduction of $167.5 \times 10^{12}$ Joules per second while the foam gives a reduction of $85 \times 10^{12} \mathrm{Joules}$ per second in the initial absorption region. A considerable low jerk is induced by the foam as compared to the solid aluminum block.

\section{Results and Discussion}

The produced foam is isotropic in nature due to its uniform structure. Isotropic structure implies that the properties are also 
non-directional [22]. While analyzing the results, the directionality of the cells cannot be ignored. Most of the metal foam in production have a closed structure, but in reality, the closed cell structure behaves like an open cell structure due to the material drawing closely to the edges due to surface tension while in a liquid state during manufacturing [22]. The main characteristics of the open-cell structure foam is the distribution of material in the form of little columns and beams that form the edges of the cell [22]. This characteristic has been unequivocally achieved by this work. One of the most decisive parameters of the foam is the relative density. The relative density is given by (2), where $\rho$ is the density of the foam and $\rho_{1}$ is the density of the solid material [22].

$$
\text { R.D }=\rho / \rho_{1}
$$

The R.D of the resultant structure is 0.77 . This indicates $23 \%$ less weight than the original solid aluminum material. The cells are shapes that resemble a skewed dodecahedron but can be approximated to a cuboid shape with material at each of the 12 edges. For such a model, there are four deformation modes: linear elasticity, non-linear elasticity, plastic collapse and various sorts of fractures [22]. This work has been predominantly in the linear elastic range. As in Figure 6(a), when the foam is compressed, it shows three regions. At low strains, the foam deforms in a linear-elastic way; then, there is a plateau of constant stress and finally, there is a region of densification where cell walls crush together [22]. The densification is not shown in Figure 6(a). When the analysis of the 2D matrix is done in order to study the deformation factors, the length of the individual walls (1) and the section of the wall $\left(t^{2}\right)$ are considered [22]. Since our test lies predominantly in the elastic region, we will use elastic models of deformation. The tested specimen clearly shows "Flattening" of the cells and hence, we will specifically use the bending failure theory proposed in [22]. For a force $F$ applied in a direction perpendicular to cell structure direction as in Figure 8, the deflection of the bending beam $\delta$ is given by (3), which is calculated from a single beam theory.

$$
\delta=\left(C_{1} F l^{3}\right) /\left(12 E_{s} I\right)
$$

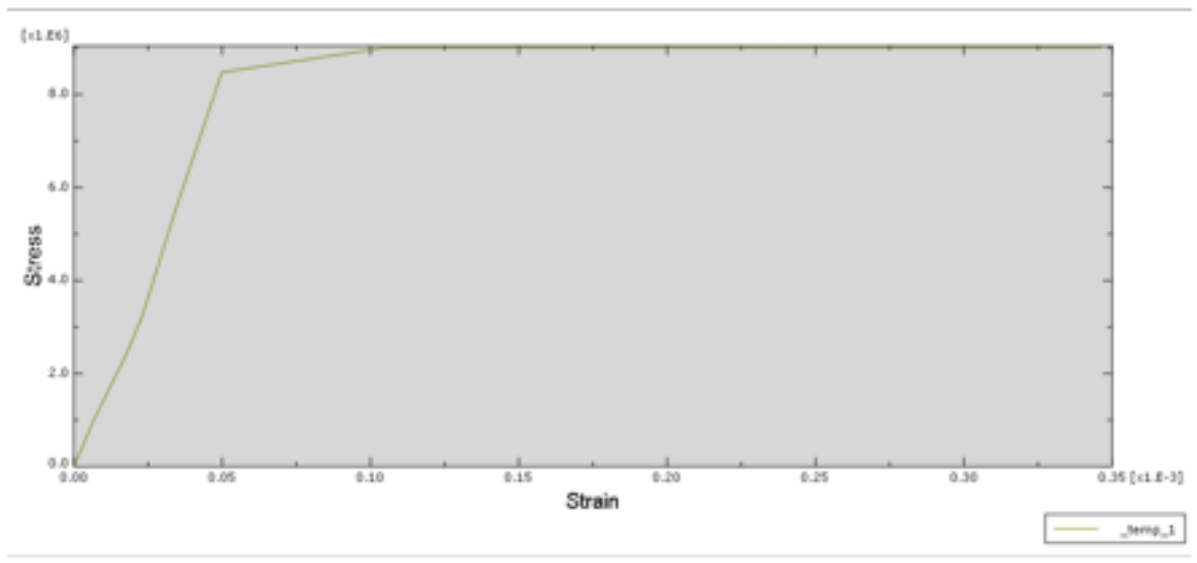

(a)

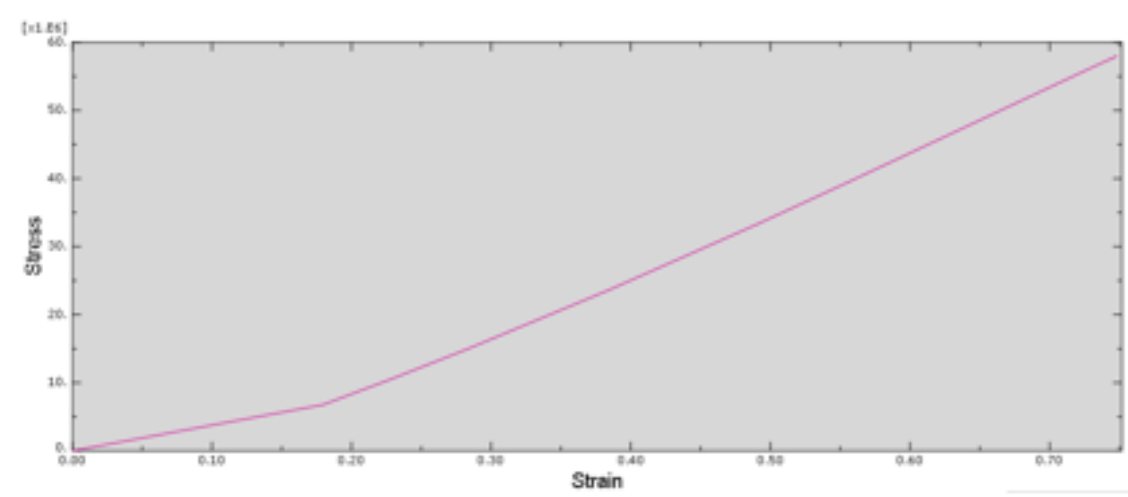

(b)

Figure 6. (a) Stress-strain graph; (b) Stress-strain graph integrated w.r.t. strain 


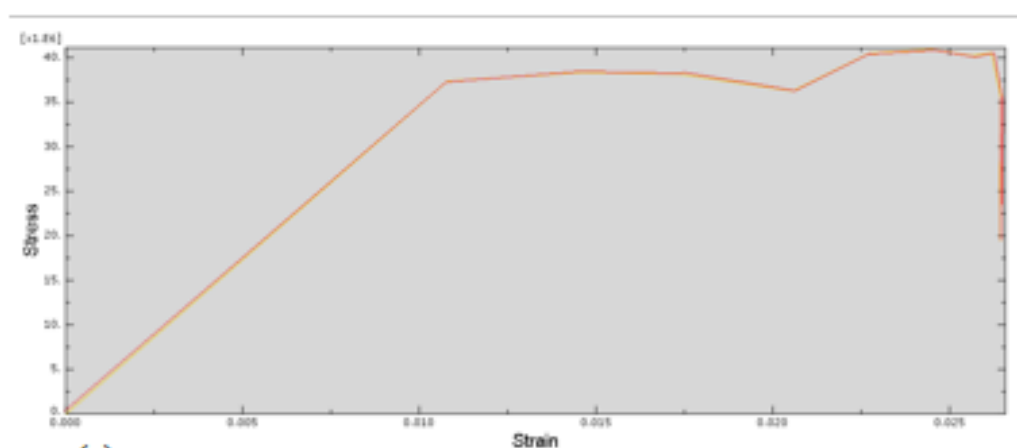

(a)

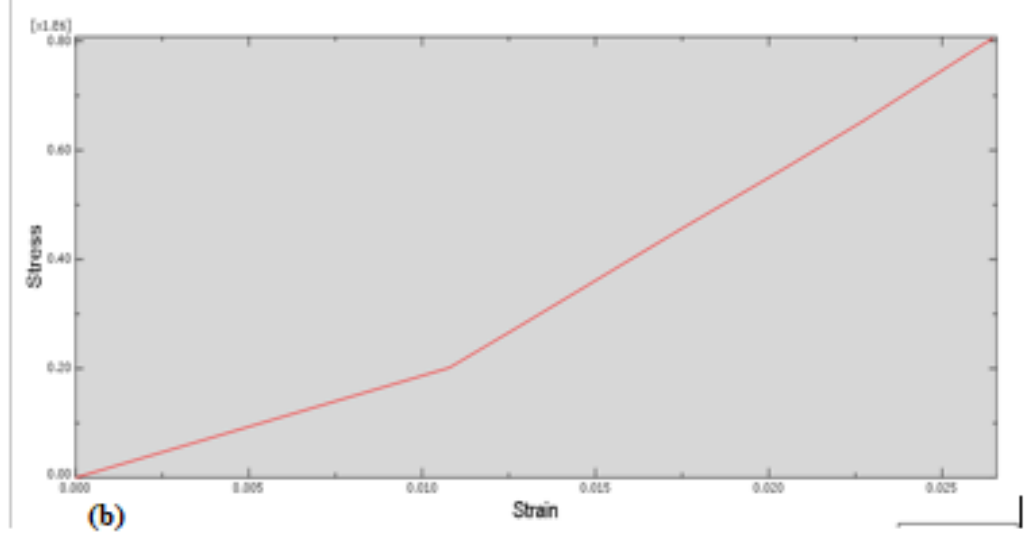

Figure 7. (a) Stress-strain plot; (b) Stress-strain integration plot

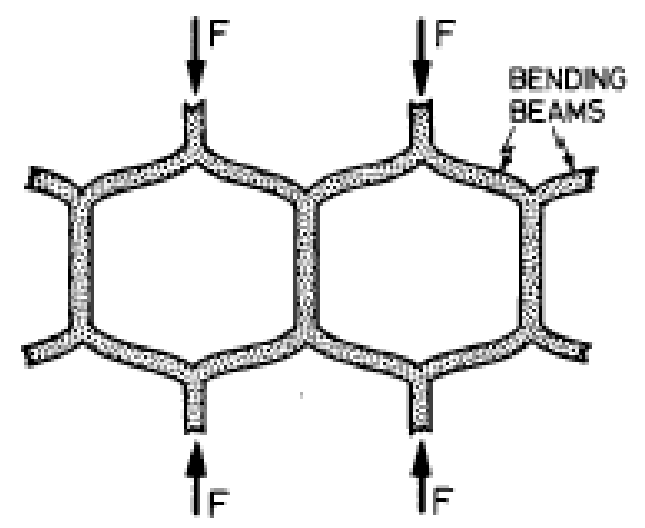

Figure 8. 2-D cell structure with applied force [23]

$C_{1}$ is a resolution Factor that depends on the cell geometry and $E_{s}$ is the Young's modulus of the solid cell wall material. $l$ is the length of the wall and $t$ is the thickness of the wall. In the foam block tested, $l$, which represents the length of the wall, is measured to be an average of $4 \mathrm{~mm}$. The $\delta$, which represents the deflection, is found to be $1.25 \mathrm{~mm}$ of the individual cell (average value). $F_{\max }$ of the UTM was $50 \mathrm{kN}$ and $E_{s}$ was taken to be $69 \mathrm{Gpa}$. It was calculated for bending in the horizontal plane and running from right to left. Substituting these values into (3) the $\mathrm{C}_{1}$ value was found to be 158.83 . Hence, this test has established a constant crucial for deflection calculation for this particular foam.

\section{Conclusions}

A homogeneous aluminum metal foam of pore size $8.0 \mathrm{~mm}$ and wall thickness $5.0 \mathrm{~mm}$ was fabricated using the process of lost foam casting (shown in Figure 9 and Figure 10). The cast product was a single matrix layer foam block. Further tests were conducted on the block to prove its crash-worthiness. The tests conducted were compression tests. To conclusively prove the effectiveness of the product, an impact analysis was done using the explicit dynamic solver provided by ABAQUS. The results conclusively proved the foam fabricated by the above discussed method is an excellent and safe impact attenuator. 


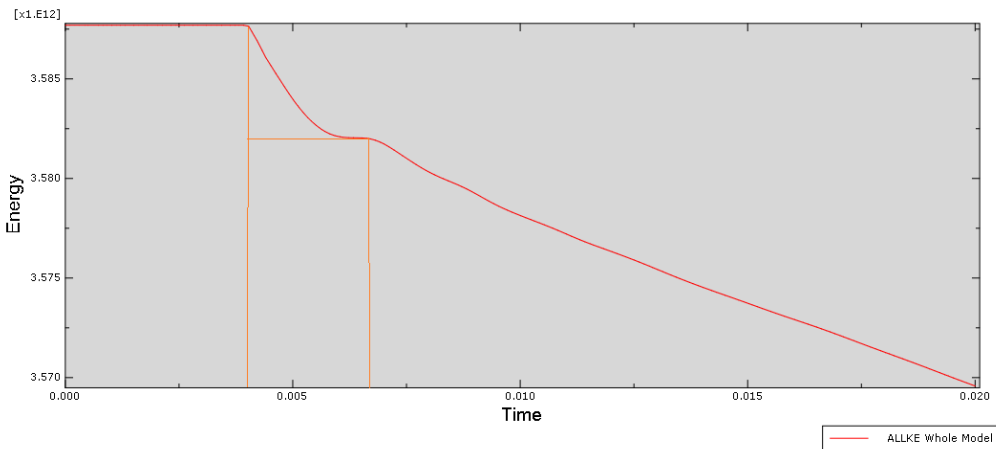

Figure 9. Energy vs Time plot of impact test with solid alumnium block

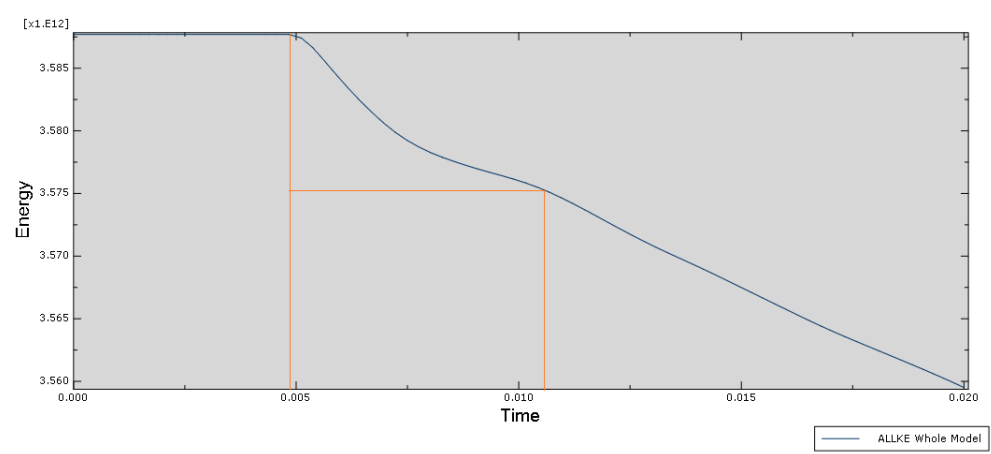

Figure 10. Energy vs Time plot of impact test with aluminum foam

\section{References}

1. J. Banhart, "Manufacture, Characterisation and Application of Cellular Metals and Metal Foams," Progress in Materials Science, Vol. 46, No. 6, pp. 559-632, 2001

2. A. K. S. Dawood and S. S. M. Nazirudeen, "New Method for the Development of Porous Grey Cast Iron Castings," International Journal of Metalcasting, Vol. 3, No. 2, pp. 43-53, 2009

3. H. P. Degischer and B. Kriszt (eds), "Handbook of Cellular Metals: Production, Processing, Applications," Wiley - VCH Verlag GmbH \& Co., 2002

4. N. Leider, "Casting Complexity in Conformable Tank," (http://content.yudu.com/we b/y5b2/0A1snzj/ModernCastingFeb2016 /flash/resourcea/22.html, accessed March 2016)

5. K. Berchem, U. Mohr, and W. Bleck, "Controlling the Degree of Pore Opening of Metal Sponges, Prepared by the Infiltration Preparation Method," Materials Science and Engineering: A, Vol. 323, No. 1, pp. 52-57, 2002

6. K. -S. Chou and M. -A. Song, "A Novel Method for Making Open-Cell Aluminium Foams with Soft Ceramic Balls," Scripta Materialia, Vol. 46, No. 5, pp. 379-382, 2002

7. J. D. Bryant, D. Wilhelmy, J. Kallivayalil, and W. Wang, "Development of Aluminium Foam Processes and Products," Materials Science Forum, Vol. 519-521, pp. 1193-1200, 2006

8. F. Binesh, J. Zamani, and M. Ghiasvand, "Ordered Structure Composite Metal Foams Produced by Casting," International Journal of Metalcasting, Vol. 12, No. 6, pp. 89-96, March 2017

9. B. H. Smith, S. Szyniszewski, J. F. Hajjar, B. W. Schafer, and S. R. Arwade, "Steel Foam for Structures: A Review of Applications, Manufacturing and Material Properties," Journal of Constructional Steel Research, Vol. 71, pp. 1-10, 2012

10. Y. Alvandi-Tabrizi and A. Rabiei, "Use of Composite Metal Foam for Improving Absorption of Collision Forces," Procedia Materials Science, Vol. 4, pp. 377-382, 2014

11. M. Garcia-Avila, M. Portanova, and A. Rabiei, "Ballistic Performance of Composite Metal Foams," Composite Structures, Vol. 125, pp. 202-211, 2015

12. Q. Qin, J. Zhang, Z. Wang, H. Li, and D. Guo, "Indentation of Sandwich Beams with Metal Foam Core," Transactions of Nonferrous Metals Society of China, Vol. 24, No. 8, pp. 2440-2446, 2014

13. J. M. Alexander, "An Approximate Analysis of the Collapse of Thin Cylindrical Shells under Axial Loading," Quarterly Journal of Mechanics and Applied Mathematics, Vol. 13, No. 1, pp. 10-15, 1960

14. P. H. Thornton, "Energy Absorption by Foam-Filled Structures," Society of Automotive Engineers, 1981

15. B. E. Lampinen and R. A. Jeryan, "Effectiveness of Polyurethane Foam in Energy Absorbing Structures," Society of Automotive Engineers, 1983

16. S. R. Reid, T. Y. Reddy, and M. D. Gray, "Static and Dynamic Crushing of Foam-Filled Sheet Metal Tubes," International Journal of Mechanical Sciences, Vol. 28, No. 5, pp. 295-322, 1986

17. T. Y. Reddy and R. J. Hall, "Axial Compression of Foam-Filled Thin-Walled Circular Tubes," International Journal of Impact 
Engineering, Vol. 7, No. 2, pp. 151-166, 1998

18. W. Abramowicz and T. Wierzbicki, "Axial Crushing of Foam-Filled Columns," International Journal of Mechanical Sciences, Vol. 30, No. 3-4, pp. 263-271, 1988

19. S. R. Guillow, R. Grzebieta, and G. Lu, "Quasi-Static Axial Compression of Thin-Walled Circular Metal Tubes Including Effects of Foam Filling," International Journal of Mechanical Sciences, Vol. 43, No. 9, pp. 2103-2123, 2001

20. W. S. Sanders and L. J. Gibson, "Mechanics of Hollow Sphere Foams," Materials Science and Engineering: A, Vol. 347, No. 12, pp. 70-85, 2003

21. W. S. Sanders and L. J. Gibson, "Mechanics of BCC and FCC hollow-sphere foams," Materials Science and Engineering: A, Vol. 352, No. 1-2, pp. 150-161, 2003

22. M. F. Ashby and R. F. M. Medalist, "The Mechanical Properties of Cellular Solids," Metallurgical Transactions A, Vol. 14, No. 9, pp. 1755-1769, 1983

23. L. Polonsky, S. Lipson, and H. Markus, "Lightweight Cellular Metal,” Mod. Cast., Vol. 39, No. 4, 1961 